\title{
Section 136 agreements in a regional health authority
}

\author{
Marinus P. Klijnsma, Annie E.A. Bartlett and Andrea Cohen
}

\begin{abstract}
The limited previous research on usage of section 136 of the Mental Health Act 1983 (MHA) has elther confined itself to description of socio-demographic and clinical data (Dunn a Fahy, 1990) or considered procectural issues solely in urban areas (Rogers \& Faulkner, 1987). This is desplte the repeated concern of the Mental Heatth Act Commiseion (1991), which has noted more widespread dificulties in the use of section 136, hichWighting individual fallures by local services to achere to the Code of Practice MHA (Department of Health and Welsh Oilice, 1990). This study attempts a region-wide survey of section 136 agreements and the corresponding frequency of use of the procedures. This is in Iine with the Reed Committee recommendations (Department of Health/Home Oilice, 1992), which priortised earty diversion from custody as an area of research, and emphasised the desirability of multi-agency section 136 coreements.
\end{abstract}

Section 136 of the MHA empowers a police officer to remove a person from a public place to a place of safety if the officer considers that the person is suffering from mental disorder, and is in immediate need of care and control. This person does not have to have committed an offence, however in most cases the behaviour of the person removed would have justified him or her being charged with an offence against public order (Robertson, 1992). The person can be detained in a place of safety for up to 72 hours so that he or she can be assessed by a doctor and approved social worker in order that suitable arrangements can be made for treatment or care. or both. The Code of Practice MHA (Department of Health and Welsh Office, 1990) indicates that good practice depends on establishing a clear policy drawn up by the local social services authority, district health authority and chief officer of police. If section 136 is used, the police should contact the relevant psychiatric and social services. The examining doctor should be where ever possible section 12 approved, and the assessment should be done by both a doctor and an approved social worker, preferably jointly, and as soon as possible.

The aim of the study was first to survey existing agreements for section 136 assessments in a health region and to compare these with the recommendations for good practice, and second to measure the frequency of use of section 136 .

\section{The study}

The health region was previously divided into 13 district health authorities (several of these have now acquired trust status but for the purposes of this study the service unit was unchanged). Within the region are 22 mental illness admission units comprising ten psychiatric hospitals, ten psychiatric wards in district general hospitals and two psychogeriatric hospitals. The method employed was telephone interview, using a semi-structured questionnaire. Contact was made with the 16 administrators who had final responsibility for all procedures involving the use of the MHA (most administrators had responsibility for entire 'districts', but in one 'district' three needed to be contacted and in another 'district' two needed to be contacted). All administrators agreed to give information. One researcher conducted all interviews.

The questionnaire addressed the following issues: the existence of section 136 policies; the place of safety; personnel involved in assessment in practice; use of hospital records to monitor the frequency of section 136s; and current problems, if any, with section 136 agreements.

In addition, contact was made on a given day with the 14 on-call trainee psychiatrists in all the relevant mental illness units to assess the realiability of the data given by the administrators. A second telephone questionnaire was conducted to examine which personnel in practice were involved in section 136 assessments.

\section{Findings}

Eight 'districts' had written section 136 policies, four did not, and the 13th 'district' contained one area with a written policy and one area without one. In five cases either the existence of a written policy or the current decision to develop one was prompted by a visit of the Mental Health Act Commission. Health, police and social services had always been involved in drawing up written policies. All written policies were 
reviewed, at periods of time varying from six months to over a year.

Details of the policies suggested that in four out of the nine areas with written policies, the place of safety was a psychiatric hospital or psychiatric ward in a district general hospital, in two it was a police station, in a further two it was both, and in one it was an accident and emergency department. In four of the five areas without a written policy the place of safety was not clear and in one instance the researcher was told that in practice it was a hospital.

It was reported that in practice, in five out of nine 'districts' with a written policy, and in two of the five 'districts' without a written policy assessments were always carried out by a section 12 approved doctor. Approved social workers were also involved in five out of nine 'districts' with written policies and only in one of the five 'districts' with no written policy. Administrators estimated that the interval between the individual's arrival at the place of safety and actual assessment was variable and often longer than six hours. In only three 'districts' were joint assessments undertaken by a section 12 approved doctor and an approved social worker within six hours.

Of the 14 (one in each district and two in the '13th' district) on-call trainee psychiatrists contacted, 13 gave the same data as the administrators on section 12 approved doctor and approved social worker involvement in practice. The trainee psychiatrists also reported variable and sometimes long intervals between arrival of the individual and assessment. In addition to the three districts with joint assessments, a further two on-call trainee psychiatrists mentioned that in their district joint assessments were common practice.

Section 136 records were kept in all eight 'districts' with a written policy, and in one of the four without a written policy. In the 13th 'district', only one area within it attempted to monitor numbers. However, four of these records were unreliable. Reasons given to explain the unreliability of records included failure to record section 136 assessments if they happened in a police station and failure to record section 136 assessments conducted in hospital if they did not result in admission. 'Districts' with reliable records indicated an annual range of 6-109 assessments. The limited reliable information precluded further analysis.

Anecdotal information shed light on the type of problems identified by administrators in connection with section 136. These included difficulties in establishing liaison with all agencies involved. including their own clinicians, affecting the development of written policies adversely. At other times the existence of a clinician with an interest in the operation of the MHA facilitated such liaison. Also, in practice, the police occasionally brought patients to hospital unannounced or as section $136 \mathrm{~s}$ but without the appropriate paperwork or even using 1959 MHA forms. Administrators commented that not only the police but also some clinicians were unfamiliar with written policies. For example, it was not unheard of for the on-call trainee psychiatrist (rarely section 12 approved) to assess a person and only call the duty consultant and duty social worker if a section under the MHA was though to be required. Alternatively a person could find him or herself 'admitted' under section 136 by the on-call trainee psychiatrist. If a consultant subsequently saw the individual, the social worker might be asked to come only if a further section was indicated.

\section{Comment}

Several of these findings warrant further discussion. The choice of administrators rather than clinicians as a source of information about section 136 policy and practice is important. Although they only receive reports of clinical practice, they were in a good position to describe policy development, the accuracy of records, the attitudes of all agencies involved, including their own clinicians and to comment on review procedures. Agreement between administrators and 13 out of 14 on call trainee psychiatrists on reports of clinical practice, suggest that this information is reliable.

The regional survey suggests that a significant number of mental health units are failing to adhere to guidelines for good practice, although there are signs that the situation region wide is improving. Only a few 'districts' actually follow the Code of Practice MHA (Department of Health and Welsh Office, 1991) and often patients were deprived of an assessment by a section 12 approved psychiatrist and approved social worker, or both. The recommendations made by Rogers \& Faulkner (1987) that there should be no admission on a section 136 but only an assessment and that approved social workers should attend all cases have not lost their relevance. Also, in nearly all 'districts' the patient on section 136 is taken to a police station first, even when the place of safety is a hospital. This practice seems difficult to avoid for organisational reasons but remains undesirable.

The region-wide variation in procedures for section 136 assessments may in part explain the very different frequency of use of section 136 in different districts in a single health region. Clearly this suggestion is tentative. Other factors beyond the scope of this study, e.g. sociodemographic differences, variation in psychiatric morbidity, variation in psychiatric service 
provision and police practice might also influence the frequency of use.

Section 136 is a cheap and potentially effective way of diverting mentally disordered persons from police custody. This can prevent them proceeding to the more costly and distressing processes of the criminal justice system. However, evidence suggests that the police see section 136 procedures as cumbersome, time-consuming and frustrating and tend to under-identify mental disorder rather than over-identify it (Dunn \& Fahy, 1990). These findings, together with our own results obtained from the health service, suggest that the current use of section 136 is unsatisfactory. In particular, we would suggest that the demonstrated absence of agreed guidelines is likely to discourage the police further from pursuing section 136 in appropriate cases and the option of early diversion from the criminal justice system to the health service is likely to be missed.

We would recommend that all district health authorities without a written policy should draw up a policy, following the Code of Practice of the Mental Health Act, in liaison with the police and social services. A psychiatrist with a special interest in the MHA among the clinical staff could facilitate this. Secondly, efforts should be made to disseminate the policy to all relevant personnel, not simply higher management. Thirdly, district health authority administrators should keep reliable records on all section 136 individuals, regardless of outcome. These records should include demographic data, time of section 136 application and time of assessment, and the profession of the assessors. Policies and records should be reviewed regularly by all parties involved and detected discrepancies between policy and practice should be addressed.

\section{References}

Department of Health AND Welsh Office (1990) Code of Practice Mental Health Act 1983. London: HMSO.

- /HOME OFFice (1992) Report of the research advisory group. Review of health and social services for mentally disordered offenders and others requiring similar services. Unpublished.

DUNN, J. \& FAHY, T. (1990) Police admissions to a psychiatric hospital. Demographic and clinical differences between ethnic groups. British Journal of Psychiatry. 166, 373-378.

Mental Health ACt Commission (1991) Fourth Blennial Report 1989-1991. London: HMSO.

RoBERTSON. G. (1992) Police disposal of mentally ill people in central London. Unpublished. Report to the Home Office.

ROGERS, A. \& FAULKNER, A. (1987) A Place of Safety. London: MIND.

Marinus P. Klijnsma, Senior Registrar, Warlingham Park Hospital, Warlingham, Surrey CR6 9YR; Annie E.A. Bartlett, Clinical Research Fellow; and Andrea Cohen, Audit Co-ordinator; Section of Forensic Psychiatry. St George's Hospital Medical School, London SW17 ORE

\section{Defeat Depression Action Week}

\section{3-11 March 1994 \\ Atms}

* to raise awareness about depression

* to reduce the stigma associated with it

* to give advice on seeking help

There will be a two mile fun run in Hyde Park, London, as part of the Defeat Depression
Action Week. This will start at 11 a.m. on Sunday, 6 March. The entry fee is $£ 3$ and the total amount received in entry fees will be matched by a commercial company and all proceeds will be donated to the Defeat Depression Campaign.

If you are interested in this event please contact Christine Gear on 0712352351. 